\title{
Justified by ideology: Why conservatives care less about corporate social irresponsibility
}

\author{
Anna Jasinenko ${ }^{\mathrm{a}, \mathrm{b}, *}$, Fabian Christandl ${ }^{\mathrm{c}}$, Timo Meynhardt ${ }^{\mathrm{a}, \mathrm{d}}$ \\ ${ }^{a}$ Dr. Arend Oetker Chair of Business Psychology and Leadership, HHL Leipzig Graduate School of Management, Jahnallee 59, 04109 Leipzig, Germany \\ ${ }^{\mathrm{b}}$ Department of Strategy, Globalization and Society, HEC Lausanne - Faculty of Business and Economics, University of Lausanne, 1015 Lausanne, Switzerland \\ ${ }^{\mathrm{c}}$ Hochschule Fresenius, University of Applied Sciences Cologne, Im MediaPark 4c, 50670 Köln, Germany \\ ${ }^{\mathrm{d}}$ Center for Leadership and Values in Society, University of St. Gallen, Dufourstrasse 40a, 9000 St. Gallen, Switzerland
}

\section{A R T I C L E I N F O}

\section{Keywords:}

System justification

Political ideology

Conservatism

CSR perception

Corporate social responsibility

Fair market ideology

\begin{abstract}
A B S T R A C T
We examine the cognitive and motivational process underlying the effect of consumers' conservatism on their corporate social responsibility (CSR) perceptions of irresponsible versus responsible companies. Building on political psychology and system justification theory, we identify and test market system justification (MSJ) as a motivated social cognition underlying ideological differences in CSR perceptions and reactions. Using four empirical studies, we find that the relatively high MSJ of conservatives (compared to that of liberals) results in less critical CSR perceptions of irresponsible companies and, thus, in less penalizing reactions. Moreover, we find that conservatism influences CSR perceptions of irresponsible companies more strongly than of responsible companies because MSJ affects only perceptions of market behaviors that threaten notions of fair markets (i.e., low CSR). The results improve predictions of consumers' perceptions and reactions to responsible and irresponsible companies.
\end{abstract}

\section{Introduction}

Consumers can be fairly unpredictable or even paradoxical in their responses to corporate social responsibility (CSR). Even though most consumers have highly positive attitudes toward CSR, not all of them act accordingly (e.g., Mohr, Webb, \& Harris, 2001; Vermeir \& Verbeke, 2006). Understanding why some consumers are highly motivated and active in penalizing irresponsible businesses (e.g., by boycotting an irresponsible company) whereas others refrain from such behaviors is not only theoretically interesting but also of high practical value for business practice. Being able to better predict which consumers appreciate CSR and why could help marketers develop need-specific targeting of consumers and thereby improve returns to CSR investments (McWilliams, Siegel, \& Wright, 2006). Prior research implies that political ideology might be a strong and easily accessible predictor of CSR-related behavior (e.g., Chin, Hambrick, \& Treviño, 2013; Gupta, Briscoe, \& Hambrick, 2017; Jung, Garbarino, Briley, \& Wynhausen, 2017). According to this line of research, conservatives are generally less concerned with CSR and hence react less critically than liberals. However, other research is inconsistent with the aforementioned pattern, implying that conservatism has no significant impact on CSR perceptions or reactions (e.g., Antonetti \& Anesa, 2017; Jost, Langer, \& Singh, 2017).
To further understand the effects of conservatism on CSR perceptions and reactions, we aim to shed light on the motivational and cognitive underpinnings of the effect, as well as on the conditions that bolster it. Thereby, we aim to contribute to a better theoretical understanding of this ideological effect, as well as of its use in marketing practice. We do so, first, by identifying and testing market system justification (MSJ; Jost, Blount, Pfeffer, \& Hunyady, 2003) as a specific form of motivated social cognition underlying ideological differences in CSR reactions. While previous studies discussed general system justification as a possible explanation for ideological differences (Jost et al., 2017; Jung et al., 2017), we argue that MSJ is a more appropriate construct to understand ideological differences in CSR reactions. Due to its relatively high content specificity and better fit for the market context of consumption (Jost, Blount, et al., 2003), it should have higher explanatory power for CSR perceptions and reactions than general system justification. Second, we examine whether the CSR performance of the evaluated company influences the effect of conservatism on CSR perceptions and reactions. Prior research shows significant effects of conservatism on CSR perceptions of irresponsible companies and penalizing reactions (Antonetti \& Anesa, 2017; Chin et al., 2013; Gupta et al., 2017; Jost et al., 2017) but inconsistent effects when focusing on the CSR perceptions of responsible companies and

\footnotetext{
* Corresponding author at: Department of Strategy, Globalization and Society, HEC Lausanne - Faculty of Business and Economics, University of Lausanne, Internef 557, 1015 Lausanne, Switzerland.

E-mail address: anna.jasinenko@unil.ch (A. Jasinenko).
} 
rewarding reactions (Antonetti \& Anesa, 2017; Gromet, Kunreuther, \& Larrick, 2013; Jost et al., 2017). We suggest that this inconsistency could result from differing effects of MSJ on the perceptions of irresponsible versus responsible companies' CSR. According to system justification theory, conservatives' relatively high system justification tendency should affect their perceptions of system-threatening aspects (i.e., low CSR; Jost, Banaji, \& Nosek, 2004) but not system-affirming aspects (i.e., high CSR). Irresponsible companies pose a major threat to the stable persistence of the market system, whereas responsible companies confirm conservatives' views that the market is fair and just and consequently needs no further justification or rationalization. Overall, the specification of the motivational and cognitive processes underlying the effect of conservatism on CSR perception, as well as the effect of the CSR performance of the evaluated company on ideological differences in CSR perceptions, allows for more specific predictions of consumers' reactions to socially irresponsible and responsible business behaviors.

\section{Theoretical background and hypotheses}

\subsection{The impact of conservatism on consumers' CSR reactions}

In recent decades, the conservatism versus liberalism distinction has been able to account for political ideology in nearly all cultural contexts (Jost, 2006). Political ideologies are "complex belief systems that incorporate, among other things, people's theories about human nature, their philosophies concerning the appropriate use of social power, status, and authority, and their moral and pragmatic convictions concerning the maximization of social and economic welfare" (Jost, Blount, et al., 2003, p. 54). Most commonly, political ideology is operationalized as a unidimensional continuum between liberal and conservative or left and right (Jost, 2017). Although there are some conceptual differences between right wing and conservative and between left wing and liberal, the terms are mostly used interchangeably in political psychology (Jost, 2017). In the following, we use the label conservatism to refer to individuals who are politically conservative or rightist rather than liberal or leftist. Research in political psychology suggests that political ideology is deeply rooted in differences in relational, epistemic, and existential needs (Jost, 2017; Jost, Glaser, Kruglanski, \& Sulloway, 2003; Jost et al., 2017). Accordingly, conservatism relates to relatively higher needs for certainty, conformity, and security (Jost et al., 2017). Based on these deeply rooted differences in basic needs and resulting emotions, conservatism is a powerful predictor for a wide range of consumer attitudes and behaviors (e.g., Han, Jung, Mittal, Zyung, \& Adam, 2019; Jung et al., 2017; Khan, Misra, \& Singh, 2013; Kim, Park, \& Dubois, 2018; Ordabayeva \& Fernandes, 2018; Septianto, Northey, \& Dolan, 2019). In the current research, we delve into the impact of conservatism on consumers' CSR perceptions and reactions.

Prior research has defined CSR as an umbrella term that "reflects the social imperatives and the social consequences of business success" concerning "the wider societal good" (Matten \& Moon, 2008, p. 405). Overall, the CSR concept is inherently subjective and thus strongly depends on individual perceptions and interpretations (Lange \& Washburn, 2012; Meynhardt \& Gomez, 2019; Murphy \& Schlegelmilch, 2013). Consequently, a publicly predominant subjective evaluation of CSR represents an approximation of (subjectively valid) true CSR performance (Meynhardt \& Gomez, 2019; Meynhardt, 2009). Even though most consumers view CSR favorably, not all of them incorporate CSR into their buying behavior (Mohr et al., 2001). Among other factors, conservatism seems to influence CSR reactions, especially for irresponsible companies. Overall, conservatives seem to be less motivated than liberals to respond to CSR misconduct (Antonetti \& Anesa, 2017; Chin et al., 2013; Gupta et al., 2017; Jost et al., 2017; Jung et al., 2017). Antonetti and Anesa (2017), for example, find that conservatism negatively affects the intention to penalize companies due to aggressive tax avoidance. Organizational research, moreover, proposes a negative relationship between conservatism and the motivation to react to insufficient CSR performance, for example, by proactively supporting CSR activities within the company (Chin et al., 2013; Gupta et al., 2017). By contrast, the effect of conservatism on consumer behaviors rewarding high CSR seems less stable than that on behaviors penalizing low CSR. On the one hand, Gromet et al. (2013) find that conservatism negatively influences the intention to buy, as well as actual consumption of, environmentally friendly products. On the other hand, Jost et al. (2017) find no significant effect of conservatism on rewarding buying behavior and show that conservatism affects high CSR rewarding behavior less than low CSR penalizing behavior. Moreover, Antonetti and Anesa (2017) look at the impact of conservatism on the ethicality perception of responsible tax strategies and the resulting reward reactions in two independent studies. The findings imply an inconsistent effect, as the first study supports the effect of conservatism on ethicality perception, while no such effect occurs in the second study (Antonetti \& Anesa, 2017). In sum, prior research indicates a stable negative effect of conservatism on penalizing reactions to low CSR and rather inconsistent effects on rewarding reactions to high CSR. It remains unclear why the effect of conservatism is especially strong for penalizing irresponsible companies but does not influence rewarding responsible companies. Shedding light on the cognitive and motivational processes underlying the effect of conservatism could help explain this conundrum and make CSR-related consumer decisions more predictable. For this purpose, we aim, first, to identify the motivational and cognitive underpinnings of conservatism's negative effect on the penalization of irresponsible companies. Second, we aim to reflect on and contrast the cognitive process for CSR reactions to irresponsible versus responsible companies.

\subsection{MSJ as conservatives' motivated social cognition in consumption contexts}

Following a "hot" cognition approach (e.g., Bargh \& Gollwitzer, 1994), Jost, Glaser, et al. (2003) suggest that the relatively strong preferences of conservatives for security, safety and order translate into motivated cognition, which influences how information is processed and evaluated. System justification theory (Jost \& Banaji, 1994; Jost et al., 2004) provides a valuable theoretical reflection of this securityrelated motivated social cognition and further specifies the underlying process. Accordingly, conservatives' specific needs amplify the tendency to justify the current system with all its social, political, and economic arrangements as inherently legitimate and fair and to perceive inequalities as part of the natural order with no need for change (Jost \& Banaji, 1994; Jost et al., 2004, 2017). According to Jost and Hunyady (2005), system justification serves a palliative function that helps in coping with unpleasant or even threatening aspects that are complicated or even impossible to resolve. For example, in the case of consumers' perceptions of irresponsible business behavior that threatens the idea of a fair and just market system, consumers have two options to cope with the unpleasant fact of irresponsibility within the market system: First, they can try to improve the situation by actively penalizing irresponsible companies and rewarding responsible companies. However, this option involves self-sacrificing activities with low probabilities of fully resolving the problem of irresponsible corporate behavior. Second, they can try to rationalize that the irresponsible company is in fact not irresponsible and free themselves from the need to act. Of course, this second option does not improve the system and could ultimately cause more consumer stress. However, the ease of system justification and immediate relief from negative emotions seem to (unconsciously) motivate especially security-oriented individuals to prefer these quick relieves over actively trying to change things (Jost \& Banaji, 1994; Jost \& Hunyady, 2005; Jost et al., 2004).

Hence, some studies concerned with the impact of conservatism on consumers' reactions to irresponsible business behaviors propose system justification as a possible theoretical explanation for the effect (Antonetti \& Anesa, 2017; Jost et al., 2017; Jung et al., 2017). However, 
Crockett and Pendarvis (2017) argue that it could be helpful to specify the justified system that drives specific consumer perceptions and behaviors. Based on the study of Jung et al. (2017), they suggest that system justification is highly context specific, and hence, each context will need to reflect a specific system. Focusing on the consumption context, we can follow the consumer-oriented findings of Jung et al. (2017) that imply that "conservatives are motivated to justify a notion of capitalism that reifies large corporations as 'the engine of the economy' and looks askance at government interventions" (Crockett \& Pendarvis, 2017, p. 502). Consequently, a market-specific form of system justification should be especially prominent in consumption contexts. The fair market ideology (Jost, Blount, et al., 2003) captures exactly this form of MSJ. Consumers inclined toward a strong fair market ideology tend "to view market-based processes and outcomes not simply as efficient but as inherently fair, legitimate, and just" (Jost, Blount, et al., 2003, p. 55). In comparison to general forms of system justification, such as general system justification (Kay \& Jost, 2003) or the belief in a just world (Dalbert, Montada, \& Schmitt, 1987; Jost \& Burgess, 2000), which provide justifications for the whole socioeconomic system, MSJ focuses on the justification of the free market system and its relation to fairness. Moreover, MSJ is closely theoretically and empirically related to economic system justification (Jost, Blount, et al., 2003; Jost \& Thompson, 2000). However, economic system justification focuses primarily on the justification of distribution inequality (e.g., income or wealth), whereas MSJ reflects a broader range of market-related outcomes (e.g., prices or employee layoffs) and focuses on the justification of the fairness of typical market processes (Jost, Blount, et al., 2003; Jost \& Thompson, 2000).

There are some indications that MSJ may have an important influence on perception and behavior in the consumption context (Caruso, Vohs, Baxter, \& Waytz, 2013; Jost, Blount, et al., 2003; Hafenbrädl \& Waeger, 2017). Caruso et al. (2013) find that exposure to money (which is prevalent in most shopping situations) activates personal tendencies to justify the market system. Furthermore, they find that money exposure also activates general system justification; however, the effect was far smaller than for the activation of MSJ. This finding implies that MSJ might be a particularly fitting form of system justification for consumption settings that works even better than general forms of system justification to explain the effects of conservatism on CSR perceptions and reactions. Moreover, Jost, Blount, et al. (2003) find that individuals with a stronger tendency to justify the market react less critically to corporate scandals. Hafenbrädl and Waeger (2017) suggest, furthermore, that managers who tend to justify the market system are less morally outraged by unfair corporate behavior and therefore tend to engage in less CSR. Based on these findings, we propose that MSJ is a fitting construct in consumption contexts because it specifically relates to the justification of processes and outcomes in markets (Caruso et al., 2013; Jost, Blount, et al., 2003). Accordingly, conservatives will tend to justify market-related behaviors and outcomes more than liberals, which translates into less critical CSR perceptions of irresponsible companies and, in turn, less penalizing reactions. Consequently, we formulate our hypotheses as follows:

H1a. MSJ mediates the effect of consumers' conservatism on their CSR perceptions of irresponsible companies.

H1b. MSJ (M1) and consumers' CSR perceptions (M2) sequentially mediate the negative effect of consumers' conservatism on their intended and actual abstention from the consumption of products or services produced by irresponsible companies.

\subsection{The asymmetric effect of conservatism for low-versus high-CSR companies}

Understanding conservatism's effect on reactions to low CSR as motivated social cognition, moreover, sheds light on the relatively weak effect of conservatism on reactions to high CSR found in prior studies (e.g., Jost et al., 2017). As hypothesized above, in a consumption context, conservatives' relatively strong tendency to justify the market could excuse irresponsible business behavior that calls the market system into question. However, this need-related motivated cognition should affect the CSR perception of responsible companies differently because these companies differ from irresponsible companies in their activation of justification needs. Specifically, we suggest that the effect of conservatism will be weaker for the CSR perception of responsible companies than for that of irresponsible companies because MSJ affects features that threaten the system (i.e., low CSR performance) but not features that support the system (i.e., high CSR performance). According to system justification theory, individuals with a tendency to justify the market system defend behaviors "when there are problems, errors, or shortcomings associated with the application of such logics" (Jost, Blount, et al., 2003, p. 80). The reason is that all these problems, errors and shortcomings pose serious threats to the very foundations of the market system and thereby imperil the safety and security of the system that conservatives particularly value (Feygina, Jost, \& Goldsmith, 2010; Jost et al., 2017). By contrast, MSJ should not affect the CSR perceptions of responsible companies because they support the idea of fair and legitimate markets by providing examples of fair and just behavior in markets through their strong CSR performance. Therefore, high CSR performance needs no further justification to keep the idea of fair markets alive, whereas low CSR performance threatens notions of fairness and the legitimacy of markets, requiring justification to be able to support it. Realistically, however, most companies with good CSR performance have at least some minor CSR issues that could also be affected by MSJ and thus result in ideological differences in consumers' CSR perceptions, which translate into comparably smaller but not always eliminated indirect effects of conservatism through MSJ on the CSR perceptions of responsible companies. In sum, we hypothesize that conservatives' relatively strong tendency to justify the market will affect the CSR perceptions of responsible companies less than those of irresponsible companies because high CSR has a minimal need for justification. Hence, we expect that the indirect effect of conservatism through MSJ on CSR perceptions (H1a) will be stronger for irresponsible than for responsible companies and, in turn, result in stronger reactions (H1b) to the CSR of irresponsible than to that of responsible companies. Consequently, we formulate the hypotheses as follows:

H2a. A company's CSR performance moderates the indirect effect of consumers' conservatism through MSJ on their CSR perceptions such that a higher MSJ has a stronger justifying effect on consumers' CSR perceptions of low-CSR companies than on those of high-CSR companies.

H2b. A company's CSR performance moderates the sequential indirect effect of consumers' conservatism through their MSJ (M1) and CSR perceptions (M2) on their CSR reactions such that the effect is stronger for the evaluation of companies with low CSR performance.

Fig. 1 summarizes our conceptual model.

To test these hypotheses, we conduct four empirical studies. In the first two studies, we aim to test the first set of hypotheses that imply that MSJ mediates the effect of conservatism on the CSR perceptions of irresponsible companies ( $\mathrm{H} 1 \mathrm{a})$ and the resulting penalizing reactions (H1b). In studies three and four, we focus on the second set of hypotheses that look at the asymmetric conservatism effect on CSR perceptions for low- versus high-CSR companies (H2a) and the resulting differences in reactions (H2b). Moreover, these latter studies validate the findings of the former studies by applying additional measures.

\section{Study 1}

The first study focuses on our first hypothesis: MSJ mediates the effect of conservatism on the CSR perception of irresponsible companies 
(H1a). We conducted an online survey in Germany that was part of the Public Value Atlas project (Public Value Atlas, 2019a). The Public Value Atlas is regularly conducted in Germany and Switzerland; the survey examines and transparently reports the public value perception of the countries' best-known organizations. For the German Public Value Atlas 2019, 11,769 German citizens evaluated the public value of 137 of the best-known organizations, which the authors preselected according to their size, brand value, or profit (Public Value Atlas, 2019b).

\subsection{Sample and procedure}

To recruit the sample for the online survey, we cooperated with the independent German market research agency forsa (forsa.de), which recruited and compensated the participants. Unlike typical online samples, forsa's offline-recruited sample includes non-internet users who answered the questionnaire via a TV set-top box (Forsa, 2019). This add-on motivates participation among older consumers, who make up a large part of the overall population but normally lack the computer literacy needed for online participation. For the Public Value Atlas 2019, 11,769 participants rated a maximum of 10 of 137 randomly assigned organizations. For our purpose, which goes beyond public value evaluation, participants who rated at least one of 12 preselected (but randomly assigned) organizations in the Public Value Atlas answered additional items related to our study. Of the 137 organizations included in the Public Value Atlas, we selected 12 that were best suited for our purpose. First, a pretest ( $N=100$ per organization) shows that all organizations have a mean of at least 4 on a six-point Likert scale of familiarity (1-“not at all familiar" to 6-"highly familiar"). High familiarity with a company implies that most consumers already know the company and (at least implicitly) have a certain CSR perception of it. Second, the 12 selected companies are consumer-oriented because we are interested in the process underlying consumer reactions to companies. Third, the companies are rather low in CSR because we expect the mediation effect to be most influential when looking at irresponsible companies (H2a-H2b). Companies could be considered irresponsible for reasons ranging from unhealthy or addictive products (Marlboro, Coca-Cola, and McDonald's), widely reported exploitative working or supplier conditions (Nike, Apple, Starbucks, Nestlé, and Amazon), recent scandals (VW, Commerzbank or Deutsche Bank) to often-criticized media sources (Bild). We used media reports from the German popular press (e.g., Rexer, 2013; Zeit, 2019) and international consumer websites for ethical consumption (ethicalconsumer.org) to guide our selection. As CSR is an inherently subjective concept (Lange \& Washburn, 2012), we do not claim to list the most objectively irresponsible companies. The primary objective of this selection is rather to provide a wide range of highly familiar consumer-oriented companies that are generally perceived to be socially irresponsible by the public.

Our subsample consists of 2476 participants with at least 258 participants per company. The age of the participants in the subsample is between 18 and $88(M=50.67, S D=17.3)$, and 54\% are male. Less than one-half of the participants $(39.9 \%)$ have a college degree or higher. Approximately one-quarter of the participants (24.4\%) report a party affiliation with the CDU, 5.0\% with the CSU, $19.7 \%$ with the SPD, $25.8 \%$ with the Greens (Grüne), 9.7\% with the Left (Die Linke), 9\% with the FDP, and $6.4 \%$ with the AfD. Overall, this distribution of socioeconomic characteristics is similar to the distribution of the German population, indicating a comparably representative sample.

Participants first rated their familiarity with each organization on a Likert scale ranging from 1 - "not at all familiar" to 6 - "highly familiar". As a measure of CSR, participants evaluated the public value of organizations that were at least somewhat familiar to them ( $\geq 4$ on the familiarity scale). For each company, they responded to four public value items (Meynhardt, 2009; $\alpha \geq 0.83$, e.g., "The organization behaves decently."). The public value concept reflects how companies contribute to the common good by fulfilling basic needs within a society (Meynhardt, 2009). According to Meynhardt and Gomez (2019), public value is a suitable measure for CSR because it provides a psychologically based understanding of individuals' subjective perspectives. Next, participants completed the fair market ideology short scale (Jost, Blount, et al., 2003; five items; $\alpha=0.77$; e.g., "The free market system is a fair system"), which measures the MSJ tendency by asking how inherently fair, just, and legitimate they perceive the free market system to be (Jost, Blount, et al., 2003). Next, participants indicated their political affiliation by selecting one of seven major parties currently in the German Federal Parliament (68 participants skipped this question and were hence not included in the final sample). Finally, participants provided demographic data, including age, sex, and level of education. Participants answered all questions, except demographic items, on a six-point Likert scale (1-“I do not agree" to 6-"I completely agree"; familiarity: 1-"not at all familiar" to 6-"highly familiar").

To account for participants' conservatism, we analyze their political party affiliation. Research shows that individuals build their political ideology to a large degree on their identification with political parties that represent specific political ideas and values (Jung et al., 2017; Mehrabian, 1996). We consider a political party conservative based on the right-left and market-state (same results) allocation of German political parties by Decker (2018). Accordingly, the CDU, CSU, FDP, and AfD are right of center on the left-right spectrum and more market oriented on the state-market spectrum, which we label as high conservatism. The Left, Greens, and SPD, in turn, are left of center on the left-right spectrum and rather state oriented on the state-market spectrum, which we label as liberalism or low conservatism. Given this allocation, $55.2 \%$ of our sample consists of ideologically liberal consumers, and $44.8 \%$ are ideologically conservative consumers. Table A1 in the appendix summarizes the means, scale reliability and correlations of all included measures.

\subsection{Analyses and results}

First, we check whether our selection of companies indeed represents socially irresponsible companies. To this end, we compare the public value perceptions of the 12 selected companies with the remaining 126 companies from the Public Value Atlas (2019a) to take into account the overall public value perception in German society. The public value scores of each selected company are in the lowest public value quartile of the Atlas. The comparatively low public value perception applies to both conservative and liberal consumers, which implies relatively low CSR performance for all 12 selected companies.

Next, we focus on the analysis of the hypothesis that MSJ mediates the effect of conservatism on the CSR perception of irresponsible companies. We analyze this hypothesized mediation effect using the SPSS macro PROCESS, which calculates 95\% confidence intervals using a bootstrap procedure with 50,000 resamples (Hayes, 2018; Model 4). We test separate models for each of the 12 companies, as only a subsample $(N>250)$ rated each company. We set political ideology as a dichotomous independent variable (high conservatism coded as " 1 " and low conservatism coded as " -1 ”), MSJ as the mediator, and perceived CSR as the dependent variable (see Table 1 for an overview of the results). First, the total effect of conservatism on CSR perception indicates whether conservatives perceive the corporate behavior of irresponsible companies as more socially responsible than liberals, as prior research suggests (Antonetti \& Anesa, 2017; Jung et al., 2017). In fact, for 10 of 12 companies, conservatism has a significant effect on consumers' CSR perception (see Table 1, fourth column). Only for the two banks (Commerzbank and Deutsche Bank) is the effect of political conservatism on CSR perception not significant, although the effect is observed in the same direction. Second, the indirect effect indicates (see Table 1, right column) whether MSJ mediates the effect of conservatism on CSR perception. The indirect effect is significant for 11 of 12 companies (indirect effect $\geq 0.054$ with the corresponding $95 \%$-CIs excluding zero). Only for the case of McDonald's is the indirect effect not significant, but it has the same tendency at a descriptive level (indirect 
effect $=0.034 ; 95 \%-\mathrm{CI}=[-0.02 ; 0.09])$. Table 1 presents all path coefficients for each company case.

Furthermore, we conduct a meta-analysis of the 12 company cases to examine the robustness of the hypothesized mediation effect of MSJ on the effect of conservatism on the CSR perception of irresponsible companies (H1a). Specifically, we run a random effects model using the $\mathrm{R}$ add-on package metafor (Viechtbauer, 2010). We analyze the overall indirect effect by using the Hedge estimator, which is unbiased with respect to the population effect size, as it provides a weighting according to the variance of each subsample effect (Cumming, 2012). The overall estimate of the effect is $0.0814(z=7.60, p<.001$, 95\%$\mathrm{CI}=[0.061 ; 0.102]$ ), indicating a highly significant indirect effect (see Fig. A1 in the appendix). Additionally, the heterogeneity of subsample effects is not significant $(Q=18.14 ; p=0.08$ ), implying that the effects do not differ due to the variability of the sample.

\subsection{Discussion}

Overall, the pattern of results of our first study corroborates for various consumer-oriented companies the first hypothesis, which states that, owing to a stronger MSJ, conservatives perceive irresponsible organizations to be more socially responsible than their liberal counterparts do. Specifically, conservatives perceive the CSR of 10 of 12 irresponsible companies as significantly higher, and the indirect effect via MSJ is significant for 11 of 12 companies. Even though there is no significant ideological difference in the CSR perceptions of the two banks, MSJ, which is always significantly related to conservatism, still has a highly significant impact on CSR perception. One explanation for the non-significant ideological difference regarding the two banks might be that the 2008 banking crisis severely threatened financial security and system prosperity in many countries. This breach of security might have threatened security-valuing conservatives so strongly that their relatively strong MSJ did not lead them to completely disregard the CSR misbehavior of the two banks. Even though the indirect effect of MSJ on CSR perception is not significant in the case of McDonald's, the meta-analysis reveals that the effect is highly significant overall with regard to irresponsible companies.

\section{Study 2}

The pattern of results in the first study supports the first hypothesis that MSJ mediates the effect of conservatism on consumers' CSR perceptions of irresponsible companies. In the second study, our goal is to replicate this finding in another country to test the robustness and generalizability of the effect to other cultures and political systems. Moreover, we investigate whether this ideologically influenced difference in CSR perception, in turn, affects consumers' reactions to irresponsible companies (H1b).

\subsection{Sample and procedure}

To recruit the sample, we cooperated with the independent Swiss market research agency intervista (intervista.ch), which invited Swiss consumers to participate in this online survey in exchange for points that are redeemable for vouchers. The final sample consists of 826 participants aged between 18 and $89(M=49.66, S D=17.90), 52.2 \%$ of whom are female. Less than one-quarter $(23.9 \%)$ of the participants have a college degree or higher. Most participants report a party affiliation with the SP $(22.7 \%)$ or the SVP (21\%). Moreover, $16.3 \%$ report a party affiliation with the FDP, $12.2 \%$ with the GLP, $9 \%$ with the GPS, 8.1\% with the BDP, 5.6\% with the CVP, and $4.9 \%$ with the EVP. Overall, this distribution of socioeconomic characteristics is similar to their distribution in the Swiss population, indicating a comparably representative sample.

For the second study, we focus on three of the 12 companies from the first study. Again, we select nationally well-known companies that are consumer oriented and low in CSR according to public opinion. As the hypothesized mediation effect of MSJ is not significant in the first study for the case of McDonald's, we include McDonald's in the second study to investigate this case further. Moreover, we include Coca-Cola as a highly consumer-oriented company that is internationally well known. In addition to these two US-based global companies, we select Nestlé, a Swiss company with global outreach. All three selected companies rank relatively low in the Public Value Atlas in 2015 and 2017, indicating relatively low CSR performance in Switzerland. In the survey, participants first observed an organization's name and logo and had to indicate their familiarity with that organization. As in the first study, only participants who were at least somewhat familiar with the company ( $\geq 4$ on the familiarity scale; 13 participants were not included in the sample due to low familiarity) subsequently evaluated the company's CSR as measured by public value (Meynhardt, 2009; four items; $\alpha \geq 0.87$ ). We measure consumers' penalizing reactions by asking about their consumption frequency during the previous year and their intention to pay more for the products or services produced by the company of interest. We average both items to calculate an index of consumers' reactions ( $\alpha \geq 0.68$ ). We interpret the withdrawal of intentions to pay more and to consume (i.e., low scores) as penalizing reactions. Although boycotting might be the most influential penalizing reaction, only a minority of consumers translates negative CSR evaluations into boycotts (Hoffmann, Balderjahn, Seegebarth, Mai, \& Peyer, 2018; Klein, Smith, \& John, 2004). Research implies that boycotting has high personal costs, which most consumers avoid even if they see CSR misconduct critically (Klein et al., 2004). Accordingly, we expect that less definite forms of penalizing reactions, such as lower willingness to pay or minimization of consumption, will reflect a broader range of consumers' penalizing reactions. Next, consumers completed the fair market ideology short scale as measure of MSJ (Jost, Blount, et al., 2003; five items; $\alpha=0.75$ ). Finally, they indicated their political party affiliation, as well as their age, sex, and level of education. Participants answered all questions, except for demographic questions, on a six-point Likert scale (1-"I do not agree" to 6-"I completely agree"; familiarity: 1-“not at all familiar" to 6-"highly familiar"; frequency: 1-"never" to 6-"very often").

As in Study 1, we use political party affiliation as a proxy for conservatism. According to Longchamp (2018), the SVP, FDP, CVP, and $\mathrm{BDP}$ are right of center on the left-right spectrum, which we label high conservatism. Conversely, the GPS, GLP, SP, and EVP are left of center on the left-right spectrum, which we label liberalism or low conservatism. Based on this allocation, $51 \%$ of consumers in our sample are ideologically conservative and $49 \%$ are ideologically liberal. Table A2 in the appendix summarizes the means, reliability and correlations of all included measures.

\subsection{Analyses and results}

First, we use the second study to replicate the first study's findings in a Swiss sample. Hence, we test whether MSJ mediates the effect of political ideology on CSR perception by using the PROCESS macro and applying the same procedure as in the first study (Hayes, 2018; Model 4). For all three company cases, the results show a significant mediation effect of fair market ideology on the effect of political ideology on public value perception (indirect effect $\geq 0.106$; all 95\%-CIs excluding zero), which corroborates the pattern of results observed in the first study. The hypothesized mediation effect also occurs for McDonald's, which was not significant in the first study (see the mediation model in Table 2). Second, we test H1b, which implies that MSJ and CSR perception sequentially mediate the effect of conservatism on consumers' reactions to irresponsible companies. For this purpose, we use the PROCESS macro sequential mediation model (Hayes, 2018; Model 6), where conservatism (high conservatism coded as "1" and low conservatism as " -1 ") is the independent variable, MSJ is the first mediator, CSR perception is the second mediator, and consumer reactions 
are the dependent variable. We test a sequential mediation model for each of the three unrelated subsamples for each company case. First, sequential mediation is significant for all three company cases (sequential indirect effect $\geq 0.041$; all $95 \%$-CIs excluding zero), corroborating our H1b. The total effect shows that conservatism has a significant influence on consumers' reactions for Coca-Cola $(b=0.234$; $t=2.16 ; p=.032)$ and Nestlé $(b=0.453 ; t=5.30 ; p<.001)$. However, there is no significant total effect of conservatism on reactions for McDonald's ( $b=0.121 ; t=1.57 ; p=.118$ ), even though, on a descriptive level, the effect shows the same tendency (see sequential mediation model in Table 2).

\subsection{Discussion}

In short, the analysis replicates the findings from Study 1 that consumers' MSJ mediates conservatism's effect on consumers' CSR perceptions (H1a). Moreover, we find that this effect extends to consumers' reactions (H1b). Specifically, we observe significant sequential mediation, where conservative consumers report a higher MSJ and, thus, perceive that irresponsible companies have higher CSR (H1a). Consequently, conservatives show weaker penalizing reactions to irresponsible companies than their liberal counterparts do (H1b). Overall, the results corroborate our first two hypotheses. Unlike the first study, in this study, we find a significant indirect effect of conservatism through MSJ on perceptions of McDonald's CSR. This finding further corroborates the hypothesized mediation effect of MSJ on the relationship between conservatism and perceptions of irresponsible companies' CSR. The inconsistency of this effect could be due to a country-specific confounder in Germany that is not existent in Switzerland. For example, McDonald's recent decline in success among German consumers (Nuque-Joo, Kim, \& Choi, 2019) could have confounded the effect of MSJ such that conservatives no longer perceive McDonald's as fundamental to the market system and thus do not justify its behavior. Furthermore, we find no total effect of conservatism on consumers' reactions for McDonald's. First, this missing total effect does not call the mediation effect into question but instead may bolster its importance. According to methodological research, a significant total effect is not required to test and interpret a mediation effect (Hayes, 2009; Shrout \& Bolger, 2002). Thus, there might still be a significant indirect effect without a total effect. Moreover, research shows that consumer reactions are very complex because a vast number of contextual (e.g., price, availability) and subjective (e.g., perceived consumer effectiveness, involvement, or perceived availability) factors influence them (De Pelsmacker, Driesen, \& Rayp, 2005; Vermeir \& Verbeke, 2006). As a result, the isolated total effects become more difficult to identify. Accordingly, other influencing factors might blur the effect of conservatism on consumers' reactions to CSR performance and, in this case, even override the total effect for McDonald's.

\section{Study 3}

In the first two studies, we focus on CSR perceptions of irresponsible companies and identified MSJ as a mediator of the effect of conservatism on CSR perceptions (H1a) and resulting reactions (H1b). In the third study, we aim to contrast the findings for irresponsible companies with those for responsible companies. According to the second set of hypotheses, we expect that the indirect effect of conservatism through MSJ on CSR perceptions will be stronger for irresponsible companies than for responsible companies (H2a) and, in turn, influence reactions to low CSR more than reactions to high CSR (H2b). Thus, we expect a moderating effect of the CSR performance (high vs. low) of the evaluated company on the indirect effect of conservatism through MSJ on CSR perception (H2a), which will, in turn, affect consumers' reactions (H2b). Moreover, we aim to test the robustness of our findings for the first set of hypotheses regarding irresponsible companies by using additional measures for our main variables. First, we use a continuous attitudinal measure of conservatism. Second, we use an extended 25item fair market ideology scale to measure MSJ. Third, we add an alternative CSR scale to the public value measure. Finally, we extend and specify the measure of the dependent variable by dividing consumer reactions into consumer intentions and behaviors, each measured by using a three-item scale. Overall, the third study allows us to test the full conceptual model (see Fig. 1), which hypothesizes that MSJ and CSR perception sequentially mediate the effect of conservatism on consumers' reactions more strongly for irresponsible companies than for responsible companies.

\subsection{Sample and procedure}

We recruited German participants by posting a link to the survey with an invitation to participate on various online platforms where consumers engage without being paid and are motivated mostly by their interest in the topic or to encourage participation in their own studies in return (i.e., Facebook.com; Surveycircle.com; Poll-Pool.com). In the invitation, we introduced the study as part of a scientific project on the topic of consumer evaluations and decisions and asked for voluntary participation of approximately ten minutes. The final sample consists of 168 German consumers aged between 18 and 59 ( $M=27.04, S D=6.08$ ), of whom $64.9 \%$ are female and $72.3 \%$ have a college degree or higher. Approximately one-half (49.4\%) of the participants are randomly assigned to the low-CSR condition and the other half $(50.6 \%)$ to the high-CSR condition. Again, we choose well-known companies from consumer-oriented sectors. To manipulate the CSR performance of the evaluated companies in each condition, we identify a responsible counterpart for each socially irresponsible company in the same industry. As in the first two studies, we select McDonald's for the low-CSR condition and Vapiano as the high-CSR counterpart because it is a comparably popular fast food restaurant that offers a contrast to McDonald's by providing freshly made and healthy food. Moreover, we select Amazon (as in Study 1) for the low-CSR condition and DM as the high-CSR counterpart because the latter is a comparably popular retailer in Germany and scores in the highest quartile in the Public Value Atlas 2019 (Public Value Atlas, 2019a). Finally, we choose Bild (as in Study 1) for the low-CSR condition and Süddeutsche Zeitung as the high-CSR counterpart because it is a highly familiar newspaper and scores in the highest quartile in the Public Value Atlas 2019.

After being randomly assigned to one of the two conditions, consumers rated their familiarity with the three companies and indicated the perceived CSR of each as measured by public value (Meynhardt, 2009; four items; $\alpha \geq 0.79$ ). As an alternative measure of CSR perception, we include a CSR scale (Currás-Pérez, Bigné-Alcañiz, \& Alvarado-Herrera, 2009; six items; e.g., "This company fulfills its social responsibilities"; $\alpha \geq 0.91$ ). This measure reflects whether consumers perceive companies as taking their environmental and social obligations seriously and incorporating them into their businesses (CurrásPérez et al., 2009). Because the CSR construct has various definitions and measures, we add this CSR scale to understand whether our findings would be generalizable to other CSR measures. Next, participants indicated their past consumption frequency of each company's products or services (last week, last month, last year; three items; $\alpha \geq 0.78$ ) and intention to penalize or reward each company (net promoter score, intention to buy, willingness to pay more; three items; $\alpha \geq 0.77$ ). As in prior studies, we interpret low scores as penalizing intentions or behaviors, indicating a withdrawal of support for the company. The questionnaire continued with the full fair market ideology scale to measure MSJ (Jost, Blount, et al., 2003; 25 items; $\alpha=0.85$ ). Next, participants indicated their conservatism by evaluating ideologically laden claims (Roberts, 1996; four items; e.g., "The profits of the big industries should be controlled by the federal government"; $\alpha=0.71$ ). We excluded two items related to social health insurance in the initial six-item scale by Roberts (1996) because social health insurance has long been incorporated into the German system and is no longer a 
matter of political ideology (Bärnighausen \& Sauerborn, 2002); including them could negatively affect validity of this measure. Moreover, we reverse-coded the items so that high scores indicate high conservatism (and low scores indicate high liberalism) to ensure comparability with our prior studies. In comparison to the previously used binary ideology allocation by partisanship, this attitudinal ideology scale allows a linear measure. Finally, participants indicated their age, sex, and level of education. Participants answered all questions, except for demographic questions, on a six-point Likert scale (1-"I do not agree" to 6-"I completely agree"; familiarity: 1-"not at all familiar" to 6-"highly familiar"; frequency: 1-“never" to 6-"very often"). Table A3 in the appendix summarizes the means, scale reliability and correlations of all included measures.

\subsection{Analyses and results}

First, we analyze the respondents' level of familiarity with the six companies because familiarity is a prerequisite for asking participants about their consumption of these companies' products and services and their CSR perceptions. The participants showed high levels of familiarity with all six companies ( $M \geq 4.82$ on a Likert scale from 1-"not at all familiar" to 6-"highly familiar"; the minimum for each company was 3). Because participants rated three companies in each condition and reliability was high for each measure and company, we summarize the evaluations of the three companies as a general score for each condition (high vs. low CSR). The reliability of the company measures remains high for the pooled scores $(\alpha \geq 0.71$; see Table A3 in the appendix). As intended, the two conditions significantly differed in perceived CSR when measured by the public value scale (high CSR: $M=3.85, S D=0.75$; low CSR: $M=2.73, S D=0.77 ; t$ $(167)=-9.70, p<.001$; Cohen's $d=1.47$ ) as well as by the CSR scale (high CSR: $M=3.47, S D=0.71$; low CSR: $M=2.46, S D=0.80$; $t(167)=-8.61, p<.001$; Cohen's $d=1.34)$. This finding indicates that CSR was in fact lower in the low-CSR condition than in the highCSR condition. The two CSR measures (i.e., public value and CSR scale) were strongly correlated $(r=0.84 ; p<.001)$, indicating generalizability to other measures of CSR.

Next, we aim to test the second set of hypotheses implying a difference in the indirect effect of conservatism through MSJ on CSR perceptions (H2a) of high- versus low-CSR companies, as well as the resulting reactions ( $\mathrm{H} 2 \mathrm{~b})$. To test $\mathrm{H} 2 \mathrm{a}$, we use a moderated mediation model and the PROCESS macro (Hayes, 2018; Model 14). Here, we define conservatism as the independent variable; consumers' CSR perceptions, as measured by the public value and the CSR scale, as dependent variables; MSJ as the mediator; and the manipulated CSR condition (high CSR coded as "1", low CSR as " -1 ") as the moderator of the effect of MSJ on CSR perceptions. To check the effect robustness for different measures, we test separate models for the public value and CSR scales as second mediators. First, the analysis reveals a significant index of moderated mediation for the model with public value as the dependent variable (index $=-0.13$; 95\%-CI $=[-0.27 ;-0.01]$ ) and the model with CSR as the dependent variable (index $=-0.14$; $95 \%$ $\mathrm{CI}=[-0.28 ;-0.02]$; see Table 3 , second and third columns, for an overview of the results). In both models, the indirect effect of conservatism through MSJ on CSR perceptions is significantly stronger for the low-CSR condition (public value: effect $=0.25$; 95\%-CI $=[0.14$; 0.37]; CSR: effect $=0.22 ; 95 \%-\mathrm{CI}=[0.11 ; 0.35]$ ) compared to the high-CSR condition (public value: effect $=0.12 ; 95 \%$-CI $=[0.02$; 0.22]; CSR: effect $=0.07 ; 95 \%-\mathrm{CI}=[-0.03 ; 0.18]$ ). A significant interaction between the CSR condition and MSJ on CSR perceptions (public value: $b=-0.18, p=.05$; CSR: $b=-0.20, p=.04$ ) implies that MSJ functions, as hypothesized, as motivated social cognition for CSR perceptions of irresponsible companies but significantly less so for responsible companies. Fig. 2 presents the conditional effect of the focal predictor - MSJ - on CSR perceptions. Additional floodlight analyses (Johnson \& Neyman, 1936; Spiller, Fitzsimons, Lynch, \& Mcclelland,
2013) reveal that participants with an MSJ score higher than 4.86 (4.59 when the CSR scale was used instead of the public value scale) did not report significantly different evaluations of CSR for low- and high-CSR companies (see Table A4 in the appendix for full Johnson-Neyman analyses).

To test $\mathrm{H} 2 \mathrm{~b}$, we estimate a moderated sequential mediation model (Hayes, 2018; Model 91), which accounts for the complete conceptual model (see Fig. 1). Here, we define conservatism as the independent variable; consumers' intentions or behaviors as dependent variables; MSJ as the first mediator; and CSR perception, as measured by public value or the CSR scale, as the second mediator. Finally, we define the manipulated CSR condition (high CSR coded as "1", low CSR as " -1 ") as the moderator of the effect of MSJ on CSR perceptions. Again, we test separate models for the public value and the CSR scale as second mediators to examine the robustness of our findings for different measures. Moreover, we run separate models for consumers' intentions and behaviors as dependent variables. The index of moderated mediation indicates that all tested mediation models differ due to the CSR condition, as all $95 \%$ confidence intervals of the index exclude zero (see the moderated sequential mediation model in Table 3). Specifically, the significantly negative index implies that the sequential mediation effect is significantly higher in the low-CSR condition than in the high-CSR condition.

\subsection{Discussion}

In the third study, we replicate the findings of the first two studies by showing an indirect effect of conservatism through MSJ on CSR perceptions (H1a) and, in turn, on consumers' intentions and behaviors (H1b) toward irresponsible companies. Moreover, we find support for the hypotheses that the effect of conservatism through MSJ on CSR perceptions (H2a) and, in turn, on consumers' reactions (H2b) is stronger when consumers evaluate low-CSR than when they evaluate high-CSR companies. That means that conservatives perceive and react to low-CSR companies less critically than liberals but show small or no significant differences in their perceptions of and reactions to high-CSR companies. Additionally, we demonstrate the robustness of our previous findings by replicating them with additional measures of the key constructs.

\section{Study 4}

Overall, the first three studies corroborate our initial hypotheses regarding MSJ as an important mediator in the relationship of conservatism, CSR perceptions ( $\mathrm{H} 1 \mathrm{a}$ ) and resulting reactions ( $\mathrm{H} 1 \mathrm{~b})$, as well as of the asymmetric mediation effect for irresponsible versus responsible companies (H2a \& H2b). However, some important questions remain that we aim to answer in the final study. First, we propose and test whether MSJ is the best-fitting form of system justification underlying the conservatism-CSR perception relationship in the context of consumption (Caruso et al., 2013; Jost, Blount, et al., 2003). Although all three studies support the notion that MSJ is an important mediator, they do not empirically contrast MSJ with other forms of system justification, such as general system justification (Kay \& Jost, 2003) or economic system justification (Jost \& Thompson, 2000). Second, we hypothesize that CSR performance will moderate the indirect effect of conservatism through MSJ on CSR perceptions (H2a) and, in turn, on reactions (H2b), which the third study corroborates. However, the strong focus on the external validity of the research design could have limitations for the internal validity of the proposed effect (see also Morales, Amir, \& Lee, 2017 for a discussion of this issue). By choosing real-life companies to operationalize high- versus low-CSR conditions, we risk the possibility that not only CSR differences but also companyspecific confounding variables, such as ethnocentrism, brand loyalty, brand preference or animosity, explain the proposed moderation effect. For this purpose, we aim to control for all company-specific 
confounders by looking at just one company and experimentally manipulating its overall CSR performance. Third, in all three studies, we look at penalizing reactions to low CSR by focusing on the (intended) withdrawal of support or rewards (i.e., low intention to consume or low past consumption frequency). However, the literature shows that consumers can go a step further in penalizing low CSR performance by completely boycotting a company (De Pelsmacker et al., 2005; Farah \& Newman, 2010; Klein et al., 2004). Thus, we add consumers' boycotting intentions as an additional expected penalizing reaction to low CSR to address a broader range of consumer reactions.

\subsection{Sample and procedure}

We recruited German participants by using the online panel platform Prolific (prolific.co), where participants receive a small payment for their participation. Recent empirical work supports the suitability of Prolific for online experiments because of its high data quality, which exceeds that of prominent alternatives such as MTurk (Peer, Brandimarte, Samat, \& Acquisti, 2017). The final sample consists of 149 German consumers aged between 18 and $59(M=29.07, S D=7.98)$, of whom $45 \%$ are female and $39.1 \%$ have a college degree or higher. Approximately one-half (49\%) of the participants were randomly assigned to the low-CSR condition and the other half (51\%) to the highCSR condition. To control for various company-specific confounding variables, we manipulated the CSR of only one company. We chose Ikea because the company is highly familiar to people in Germany, highly consumer-oriented and ranks in the middle group of the Public Value Atlas (2019). By selecting a company that has a medium public value ranking, we expect to be able to manipulate CSR performance in positive and a negative direction.

First, participants indicated their age, sex, and level of education. Next, participants completed the liberalism scale from Study 3 that we reverse-coded to measure conservatism (Roberts, 1996; four items; $\alpha=0.72$ ). Afterward, participants answered four different system justification scales in a randomized order. In addition to the fair market ideology scale that we use in all prior studies to measure MSJ (Jost, Blount, et al., 2003; 25 items; $\alpha=0.89$ ), we include the general system justification scale (Kay \& Jost, 2003; eight items; e.g., "In general, I find society to be fair"; $\alpha=0.81$ ) and the belief in a just world scale (Dalbert et al., 1987; six items; e.g., "By and large, I think people get what they deserve"; $\alpha=0.83$ ). Moreover, we include a pretested short version of the economic system justification scale (Jost \& Thompson, 2000; seven items; e.g., "Equal distribution of resources is unnatural"; $\alpha=0.78$ ). We include a short version of the economic system justification scale because the initial 17-item scale showed little differentiation from the fair market ideology scale (pre-study in Germany with $N=620: r=0.78 ; p<.001$ ), thus indicating possible problems resulting from multicollinearity. To address this issue, we selected the seven items with the lowest correlations with the fair market ideology scale but high correlations with the initial economic system justification scale (see Table A5 in the appendix for the analysis). After completing the system justification scales, participants received a short sustainability assessment of Ikea provided by an expert that either emphasized the company's negative CSR aspects (low-CSR condition) or its positive CSR aspects (high-CSR condition). Thus, participants in the low-CSR condition read that Ikea sells many plastic products that are harming the environment and produces many products in developing countries to save money. In the high-CSR condition, participants read that Ikea offers many products from recycled materials that are environmentally friendly and invests in good working conditions for their producers in developing countries (see Table A6 in the appendix). After they read this information, we asked the participants about their perceptions of Ikea's CSR, using the public value scale (Meynhardt, 2009; four items; $\alpha=0.78$ ) and the CSR scale (Currás-Pérez et al., 2009; six items; $\alpha=0.94)$. In the next step, we asked about participants' reward intentions (net promoter score, intention, willingness to pay more; three items; $\alpha=0.73$ ), as well as their willingness to boycott Ikea (Farah \& Newman, 2010; six items; e.g., "I intend to start/keep boycotting Ikea"; $\alpha=0.93$ ). Finally, participants indicated their familiarity with Ikea prior to the study. Participants answered all questions, except for demographic questions, on a six-point Likert scale (1-"I do not agree" to 6-"I completely agree"; familiarity: 1-"not at all familiar" to 6-"highly familiar"). Table A7 in the appendix summarizes the means, scale reliability and correlations of all included measures.

\subsection{Analyses and results}

First, we find that Ikea was highly familiar to the participants ( $M=5.30, S D=1.00$; the minimum was 3 ), which made it comparable to the well-known firms used in the three prior studies. As in Study 3, the public value and CSR scale, which we use to measure CSR perceptions, are highly correlated ( $r=0.78 ; p<.001$ ). To be concise, we focus this analysis on the public value scale as a CSR measure and report the very similar results obtained using the CSR scale in the appendix (see Tables A8-A10). Moreover, we find that the two conditions (high vs. low CSR) varied significantly in their CSR perception (high CSR: $M=3.93, S D=0.91$; low CSR: $M=3.06, S D=1.03 ; t$ (1 4 8) $=-5.50, p<.001$; Cohen's $d=0.92$ ). This finding indicates that our manipulation of Ikea's CSR performance was successful.

The first aim of this study is to compare the mediation effect of the MSJ on the relation between conservatism and CSR perception to other system justifying ideologies, such as economic system justification (Jost \& Thompson, 2000), general system justification (Kay \& Jost, 2003), and belief in a just world (Dalbert et al., 1987). For this purpose, we conduct a parallel mediation analysis using the SPSS macro PROCESS (Hayes, 2018; Model 4), where we define conservatism as the independent variable, CSR perception as measured by public value as the dependent variable and the four system justification ideology scales as parallel mediators. We expect that the effect of conservatism and system justification is stronger for low versus high CSR for the evaluated company; thus, we run this mediation analysis only for participants in the low-CSR condition $(N=73)$. Our results show that the total effect of conservatism on CSR perception (total effect $=0.41 ; \mathrm{p}<.001$ ) is significantly mediated by the four system justification scales (summarized indirect effect $=0.35 ; 95 \%$-CI $=[0.09 ; 0.60]$; direct effect $=0.07 ; 95 \%$ $\mathrm{CI}=[-0.22 ; 0.36]$; see Table A7 for a summary of the results). As expected, conservatism positively influenced all four system justification scales $(b \geq 0.31 ; p<.001)$. However, MSJ is the only significant mediator among the four system justification scales. Specifically, MSJ (indirect effect $=0.29 ; 95 \%-\mathrm{CI}=[0.06 ; 0.54]$ ) has a stronger indirect effect than economic system justification (indirect effect $=0.00$; 95\%$\mathrm{CI}=[-0.19 ; 0.22]$ ), general system justification (indirect effect $=0.01$; $95 \%$-CI $=[-0.18 ; 0.19]$ ) and belief in a just world (indirect effect $=0.04 ; 95 \%-C I=[-05 ; 0.11])$. We obtain similar results when we define the CSR scale instead of the public value scale as the dependent variable (see Table A8 in the appendix).

The second aim of this study is to validate that the indirect effect of conservatism through MSJ on CSR perceptions (H2a), and in turn on reactions $(\mathrm{H} 2 \mathrm{~b})$, is stronger when consumers evaluate low-CSR than when they evaluate high-CSR companies. For the analysis of H2a, we use the moderated mediation model of the PROCESS macro (Hayes, 2018; Model 14). Here, we define conservatism as the independent variable; consumers' CSR perceptions, as measured by public value, as the dependent variable; MSJ as the mediator; and the CSR performance condition (high CSR coded as "1", low CSR coded as "-1") as the moderator of the effect of MSJ on CSR perceptions. First, the analysis reveals a significant index of moderated mediation for the model with public value as the dependent variable (index $=-0.36$; 95\%$\mathrm{CI}=[-0.61 ;-0.10]$; see the moderated mediation model in Table A9 in the appendix for an overview of the results). Specifically, the indirect effect of conservatism through MSJ on CSR perceptions is significantly stronger for the low-CSR-performance condition (effect $=0.41$; 95\%- 
$\mathrm{CI}=[0.24 ; 0.62])$ than for the high-CSR-performance condition (effect $=0.06$; 95\%-CI $=[-0.14 ; 0.25]$ ) and only significant in the lowCSR, but not high-CSR condition. A significant interaction of CSR condition and MSJ on CSR perceptions $(b=-0.41, p<.001)$ implies that MSJ functions, as hypothesized, as motivated social cognition for CSR perceptions of irresponsible companies, yet significantly less so for responsible companies (see Fig. A2 in the appendix). Additional floodlight analyses (Johnson \& Neyman, 1936; Spiller et al., 2013) reveal that participants with an MSJ score higher than 3.68 perceived high-CSR companies to not be significantly higher in CSR than low-CSR companies. Moreover, participants with an MSJ score of 5.37 or higher even perceived low-CSR companies to be significantly higher in CSR than high-CSR companies (see Table A10 in the appendix for the full Johnson-Neyman analyses).

To test $\mathrm{H} 2 \mathrm{~b}$, we run a moderated sequential mediation model (Hayes, 2018; Model 91) that represents our conceptual model (see Fig. 1). Here, we define conservatism as the independent variable; MSJ as the first mediator; CSR perception, as measured by public value, as the second mediator; and rewarding intention or boycott intention as the dependent variable (using two separate models for each dependent variable). We use the CSR performance condition as a moderator of the relationship between MSJ and CSR perception (with the high-CSR condition coded " 1 " and the low-CSR condition coded " -1 "). The analysis reveals significant moderated sequential mediation when the dependent variable is reward intention (index $=-0.23 ; 95 \%-\mathrm{CI}=[-0.44 ;-0.06]$ ) as well as intention to boycott (index $=0.21 ; 95 \%-\mathrm{CI}=[0.05 ; 0.41]$; see, for an overview of the results, Table A9 in the appendix). Specifically, the results show that the effect of conservatism on the intention to reward Ikea, sequentially mediated by MSJ and CSR perception, is significantly stronger in the low-CSR condition (effect $=0.27 ; 95 \%$-CI $=[0.13$; $0.45]$ ) than in the high-CSR condition (effect $=0.04 ; 95 \%$-CI $=[-0.09$; 0.16]). In turn, the effect of conservatism on the intention to boycott, sequentially mediated by MSJ and CSR perception, is also significantly stronger in the low-CSR condition (effect $=-0.24$; 95\%-CI $=[-0.41$; $-0.11]$ ) than in the high-CSR condition (effect $=0.03$; $95 \%$ $\mathrm{CI}=[-0.14 ; 0.09])$. In fact, the sequentially mediated effect of conservatism on CSR reactions was significant in the low-CSR condition but not in the high-CSR condition. We obtain similar results when we define the CSR scale instead of the public value scale as the first mediator (see the moderated sequential mediation model in Table A9 in the appendix).

\subsection{Discussion}

In the fourth study, we first corroborate the role of MSJ as a crucial mediator of the relationship between conservatism and CSR perception for irresponsible companies (H1a) in comparison to other system justification ideologies. Specifically, our results imply that other system justification ideologies, such as economic system justification, general system justification or belief in a just world, do not explain the ideological differences in CSR perception better than MSJ does. Second, we also corroborate our hypothesis that the indirect effect of conservatism through MSJ has a stronger impact on CSR perception when the evaluated company shows low rather than high CSR (H2a). This asymmetric effect on CSR perceptions also translates into differences in the effect on CSR reactions (H2b). Specifically, we find a stronger indirect effect of conservatism through MSJ and CSR perceptions on consumers' rewarding intentions in the low-CSR condition than in the high-CSR condition. In fact, there was no significant indirect effect of conservatism on CSR perceptions and reactions in the high-CSR condition, implying that conservatives and liberals appreciate high CSR similarly. In comparison to Study 3, which supports these hypotheses, the fourth study examines the effect in a controlled experimental setting focusing on only one firm and thereby avoiding company-specific confounding variables. Third, the results also imply that the conservatism effect on CSR perception affects boycotting intentions to a similar degree because it affects reward withdrawal intentions, as tested in prior studies.
Specifically, we find that the indirect effect of conservatism through MSJ and CSR perceptions influenced boycotting intentions significantly more in the low-CSR-performance condition than in the high-CSR-performance condition.

\section{General discussion}

Our four empirical studies support the initial hypotheses that MSJ mediates the impact of conservatism on consumers' CSR perceptions of irresponsible companies, which in turn influences consumers' reactions. Specifically, we find that conservative consumers report relatively high MSJ; therefore, they perceive the CSR of low-CSR companies to be more favorable, and as a result, they penalize those companies less than their liberal counterparts do. Moreover, we find that the indirect effect of conservatism through MSJ applies less to the CSR evaluations of responsible companies than to those of irresponsible companies, which in turn translates into fewer ideological differences in consumer reactions to responsible companies than in those to irresponsible companies. Overall, these findings contribute to a better understanding of the effect of conservatism on consumers' CSR perceptions and reactions by specifying the underlying motivational and cognitive process and by shedding light on the asymmetric effect of CSR perceptions on irresponsible versus responsible companies. In sum, we are confident that these results are robust and generalizable because we tested the main hypotheses for various consumer-oriented companies from different industries in two different countries (Germany and Switzerland) with various population-representative samples. Moreover, we used different measures for the main constructs.

\subsection{Implications for research}

Previous studies have shown a stable effect of conservatism on reactions to irresponsible business behavior (Antonetti \& Anesa, 2017; Jost et al., 2017; Jung et al., 2017) but an inconsistent effect on reactions to responsible business behavior (Antonetti \& Anesa, 2017; Jost et al., 2017). In this study, we first specify the cognitive and motivational process underlying the effect of conservatism to understand why conservatism influences CSR reactions to irresponsible companies. Based on system justification theory (Jost, Blount, et al., 2003; Jost et al., 2004), we propose and test the idea that MSJ is the best-fitting motivated social cognition that explains the effect of conservatism on CSR perceptions and related reactions. As hypothesized, our analyses in Study 4 imply that MSJ is a better fitting form of system justification than more general forms (i.e., general system justification, belief in a just world) or related constructs (i.e., economic system justification). Second, we contrast the effect of conservatism on the CSR perceptions of responsible versus irresponsible companies to shed light on possible asymmetry in the conservatism effect. Here, we find that the indirect effect of conservatism through MSJ affects the CSR perceptions of irresponsible companies more strongly than those of responsible companies. The asymmetric effect on CSR perceptions also translates into an asymmetric effect of conservatism on CSR reactions. Overall, these findings extend the understanding of how conservatism influences the CSR reactions found in prior research by specifying the underlying process and shedding light on the asymmetric effect on responsible versus irresponsible companies. These new insights have the potential to resolve some inconsistencies from the literature by highlighting that conservatives' relatively high MSJ less strongly affects perceptions of responsible companies' CSR than of irresponsible companies' CSR, which explains the relatively weak effect on reactions to high-CSR companies compared to low-CSR companies found in prior research.

\subsection{Managerial implications}

In times of strong political polarization, segmentation based on political ideology is a powerful tool to correctly understand and 
approach the specific needs and values of politically motivated target groups (Jung et al., 2017; Septianto et al., 2019). In most countries, there are publicly available data on voting behavior that help to segment geographic areas on a liberalism-conservatism continuum (e.g., Jung et al., 2017). Moreover, data from social media allow for the identification of the political ideology users on an individual level (Merrill, 2016; Septianto et al., 2019). Accordingly, practitioners have many opportunities to track the political ideologies of individual consumers or specific areas relatively easily. Our research helps to address these segments more appropriately when addressing CSR. For example, the findings imply that liberals perceive CSR misconduct more critically than conservatives do, and accordingly, they are ready to penalize these companies more strongly. Consequently, companies with CSR issues should invest in CSR marketing, especially when approaching liberal consumers. The results of Study 4, for example, show that positive and negative CSR arguments could matter, especially for liberal consumers, and significantly influence their intentions. Moreover, we find that conservatism has only a negligible effect on the CSR perceptions of responsible companies. Specifically, our analyses show that conservatives and liberals perceive the CSR of responsible companies equally well. Accordingly, political segmentation does not seem suitable for promoting high-CSR companies. Instead, high-CSR companies should communicate their CSR achievements independent of political ideology. Overall, our findings help to predict consumers' CSR reactions to irresponsible and responsible companies more precisely.

\subsection{Limitations and future research}

Although we believe that the overall pattern of results in our four empirical studies is robust, the topic of ideological differences in the consumer context leaves many interesting possibilities for future research. For example, it would be interesting to extend our findings to perceptions of other socially relevant misbehaviors. Our results show that conservatives are less critical when evaluating CSR misconduct. However, studies suggest that in other contexts, conservatives can be even more critical than liberals. Jung et al. (2017), for example, suggest that conservatives are more critical in service scenarios than liberals are. Moreover, a study by Bhattacharjee, Berman, and Reed (2015) shows less moral decoupling among conservatives than among liberals when evaluating the performance of individuals who behaved immorally. Interestingly, the studies that indicate that conservatism results in more critical ethicality evaluations (Bhattacharjee et al., 2015; Jung et al., 2017) focus on perceptions of individual behavior. In contrast, our study suggests that conservatism results in less critical ethicality evaluations and focuses on the evaluation of institutionalized corporate behavior. This difference is consistent with system justification theory, which suggests that individuals tend to justify the misconduct of predominant institutionalized actors (Jost et al., 2004). Future research could elaborate on whether there is a difference in the conservatism effect for perceptions of individual versus institutionalized behavior or whether other factors influence this effect. The direction of causality of the studied effect is not completely resolved. Do consumers perceive CSR differently because of their ideology, or is their ideology a result of different perceptions? Analyses of reversed-ordered mediators (i.e., where CSR perception influences MSJ) were not significant, supporting the hypothesized direction of causality (see Table A11 in the appendix). Moreover, theoretically, political ideology is a highly stable construct based on deeply held beliefs and needs and is incorporated into consumers' personalities (Jost et al., 2017; Jung et al., 2017), whereas CSR perception is prone to both perceptual bias and framing effects (Lange \& Washburn, 2012). Hence, the direction of causality we propose in the conceptual model seems theoretically valid. From a methodological perspective, it would be ideal to experimentally manipulate ideology to address causality. However, research suggests that ideology cannot be quickly coerced or manipulated and changes only after years of processes, such as adaptation or replacement (Haack \& Sieweke, 2018; Jost et al., 2017; Jung et al., 2017). Hence, future studies could focus on societies where an ideological shift occurs over time (e.g., the transition in East Germany from a socialist to a capitalist system, as used in Haack \& Sieweke, 2018). From a theoretical perspective, moreover, it would be highly interesting to relate conservatism to dynamic complexity theories, in particular, the theory of synergetics (Haken, 1984; Meynhardt, Chandler, \& Strathoff, 2016). Our findings focus predominantly on the micro-level analysis by asking how consumers' conservatism influences their perceptions and reactions. However, conservatism is not an isolated characteristic but is highly embedded in society and its interaction with groups and individuals. The theory of synergetics takes the complexity of multilevel interactions into account and could therefore help reflect on the impact of political ideologies from a broader perspective (Haken, 1984; Meynhardt et al., 2016). Accordingly, political ideology could constitute an important order parameter resulting from changing macro-level properties (i.e., a growing ideological gap) and influencing micro-level evaluations (Meynhardt et al., 2016).

\section{Declaration of Competing Interest}

The authors declare that they have no known competing financial interests or personal relationships that could have appeared to influence the work reported in this paper.

\section{Appendix A}

See Figs. 1 and 2 and Tables 1-3.

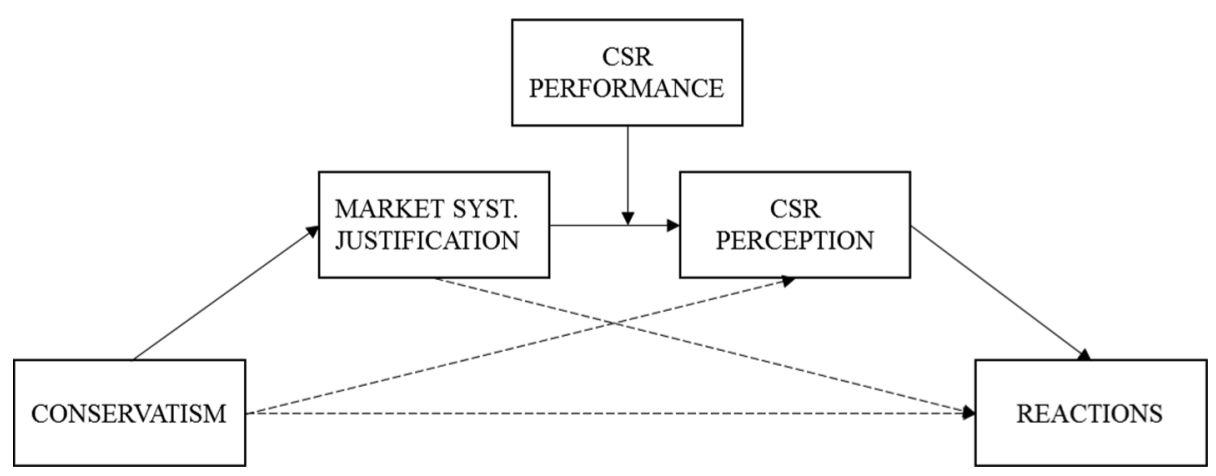

Fig. 1. Conceptual model. 


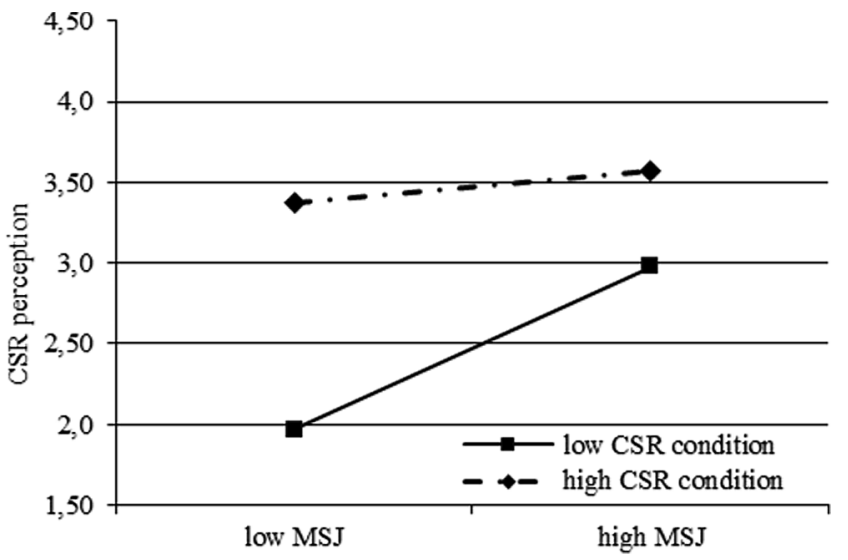

Fig. 2. Interaction effect of market system justification (MSJ) and corporate social responsibility (CSR) condition on CSR perceptions in Study 3.

Table 1

Study 1: Sample size with number of conservatives (cons.), means of perceived CSR of irresponsible organizations and unstandardized path coefficients of the hypothesized mediation, where conservatism (CON) is the independent variable, market system justification (MSJ) the mediator, and CSR perception (CSR) the dependent variable.

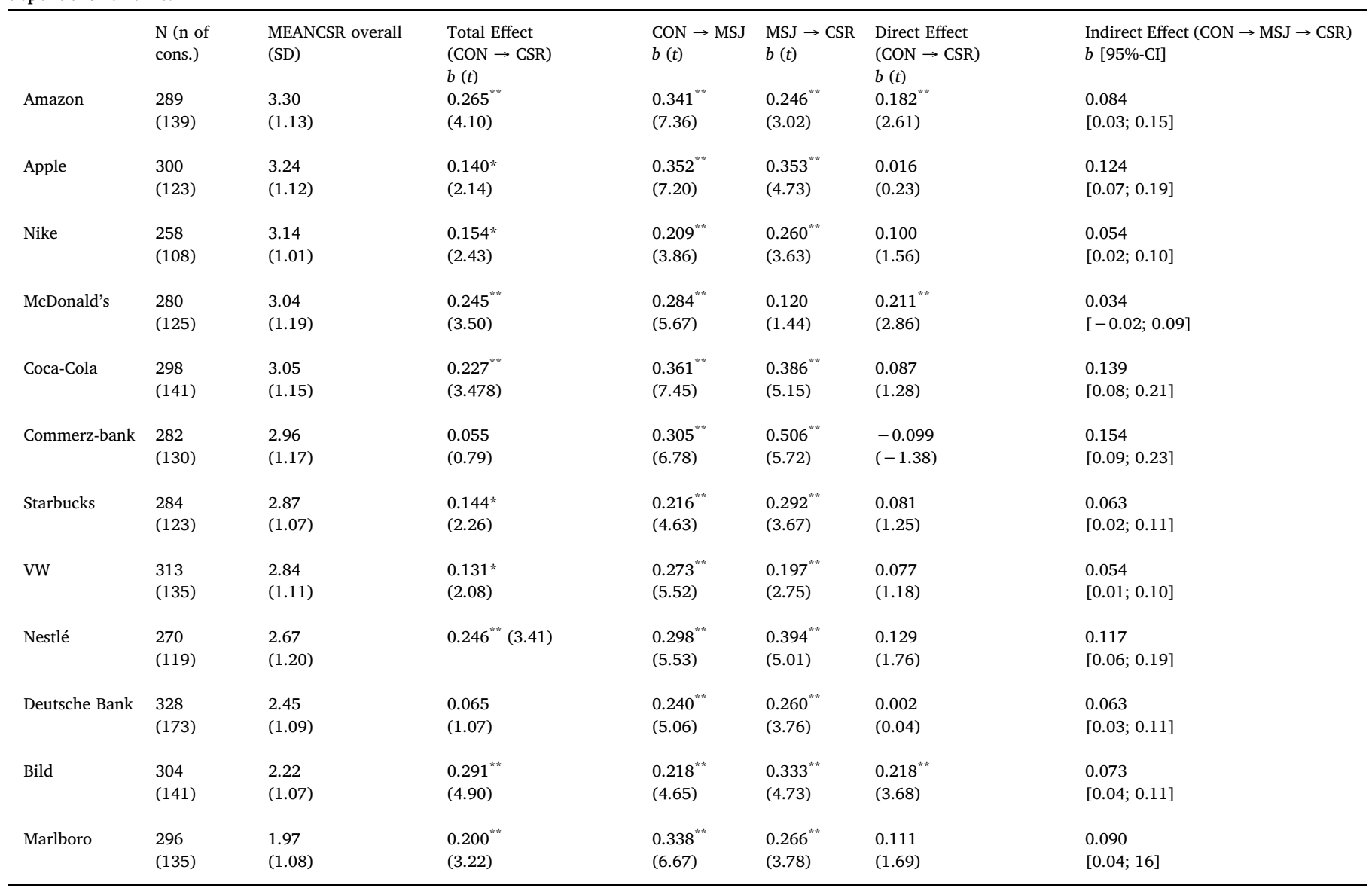

Note: ${ }^{*} p<.05,{ }^{* *} p<.01$. 
Table 2

Study 2: Unstandardized mediation coefficients of the mediation models and sequential mediation model for each company. In the mediation model, conservatism (CON) is the independent variable, MSJ the mediator, and CSR perception (CSR) the dependent variable. In the sequential mediation model, conservatism (CON) is the independent variable, MSJ the first mediator, CSR perception (CSR) the second mediator and consumers' reaction (RA) the dependent variable.

\begin{tabular}{|c|c|c|c|c|c|c|}
\hline & \multicolumn{3}{|c|}{ Mediation Model } & \multicolumn{3}{|c|}{$\underline{\text { Sequential Mediation Model }}$} \\
\hline & $\begin{array}{l}\text { Total Effect } \\
(\mathrm{CON} \rightarrow \mathrm{CSR}) \\
b(t)\end{array}$ & $\begin{array}{l}\text { Direct Effect } \\
(\mathrm{CON} \rightarrow \mathrm{CSR}) \\
b(t)\end{array}$ & $\begin{array}{l}\text { Indirect Effect } \\
(\mathrm{CON} \rightarrow \mathrm{MSJ} \rightarrow \mathrm{CSR}) \\
b[95 \%-\mathrm{CI}]\end{array}$ & $\begin{array}{l}\text { Total Effect } \\
(\mathrm{CON} \rightarrow \mathrm{RA}) \\
b(t)\end{array}$ & $\begin{array}{l}\text { Direct Effect } \\
(\mathrm{CON} \rightarrow \mathrm{RA}) \\
b(t)\end{array}$ & $\begin{array}{l}\text { Sequential Mediation }(\mathrm{CON} \rightarrow \mathrm{MSJ} \rightarrow \mathrm{CSR} \rightarrow \mathrm{RA}) \\
b[95 \%-\mathrm{CI}]\end{array}$ \\
\hline McDonald's & $\begin{array}{l}0.164^{2 * k} \\
(2.63)\end{array}$ & $\begin{array}{l}0.058 \\
(0.91)\end{array}$ & $\begin{array}{l}0.106 \\
{[0.05 ; 0.17]}\end{array}$ & $\begin{array}{l}0.121 \\
(1.57)\end{array}$ & $\begin{array}{l}0.057 \\
(0.72)\end{array}$ & $\begin{array}{l}0.041 \\
{[0.01 ; 0.07]}\end{array}$ \\
\hline Coca-Cola & $\begin{array}{l}0.228^{* * *} \\
(2.94)\end{array}$ & $\begin{array}{l}0.107 \\
(1.36)\end{array}$ & $\begin{array}{l}0.121 \\
{[0.06 ; 19]}\end{array}$ & $\begin{array}{l}0.234^{*} \\
(2.16)\end{array}$ & $\begin{array}{l}0.124 \\
(1.25)\end{array}$ & $\begin{array}{l}0.110 \\
{[0.05 ; 0.19]}\end{array}$ \\
\hline Nestlé & $\begin{array}{l}0.484^{\text {k*k }} \\
(6.69)\end{array}$ & $\begin{array}{l}0.235^{* * *} \\
(6.69)\end{array}$ & $\begin{array}{l}0.249 \\
{[0.17 ; 0.35]}\end{array}$ & $\begin{array}{l}0.453^{k * k} \\
(5.30)\end{array}$ & $\begin{array}{l}0.156 \\
(1.89)\end{array}$ & $\begin{array}{l}0.118 \\
{[0.06 ; 0.19]}\end{array}$ \\
\hline
\end{tabular}

Note: $* p<.05, * * p<.01$.

Table 3

Study 3: Unstandardized conditional effects of the moderated mediation model (model 1a and 2a), the moderated sequential mediation model (model 1b-4b) and the index of moderated mediation with $95 \%$ confidence intervals. In each model, conservatism (CON) is the independent variable, MSJ the first mediator and the CSR condition the moderator variable. In model $1 \mathrm{a}$, public value (PV) is the dependent variable, and in model $1 \mathrm{~b}$ and $3 \mathrm{~b}$, public value is the second mediator. In model $2 \mathrm{a}$, CSR is the dependent variable, and in model $2 \mathrm{~b}$ and $4 \mathrm{~b}$, CSR is the second mediator. Consumers' intention is the dependent variable in model $1 \mathrm{~b}$ and $2 \mathrm{~b}$, and consumer behavior is the dependent variable in model $3 \mathrm{~b}$ and $4 \mathrm{~b}$.

\begin{tabular}{|c|c|c|c|c|c|c|}
\hline \multicolumn{3}{|l|}{ Moderated Mediation Model } & \multicolumn{4}{|c|}{ Moderated Sequential Mediation Model } \\
\hline Low CSR Condition & $\begin{array}{l}0.25 ; \\
{[0.14 ; 0.37]}\end{array}$ & $\begin{array}{l}0.22 \\
{[0.11 ; 0.35]}\end{array}$ & $\begin{array}{l}0.139 \\
{[0.08 ; 0.22]}\end{array}$ & $\begin{array}{l}0.105 \\
{[0.05 ; 0.18]}\end{array}$ & $\begin{array}{l}0.075 \\
{[0.03 ; 0.14]}\end{array}$ & $\begin{array}{l}0.052 \\
{[0.01 ; 0.11]}\end{array}$ \\
\hline Index of Moderated Mediation & $\begin{array}{l}-0.13 \\
{[-0.27 ;-0.01]}\end{array}$ & $\begin{array}{l}-0.14 \\
{[-0.28 ;-0.02]}\end{array}$ & $\begin{array}{l}-0.072 \\
{[-0.15 ;-0.00]}\end{array}$ & $\begin{array}{l}-0.069 \\
{[-0.14 ;-0.01]}\end{array}$ & $\begin{array}{l}-0.039 \\
{[-0.09 ;-0.01]}\end{array}$ & $\begin{array}{l}-0.034 \\
{[-0.08 ;-0.01]}\end{array}$ \\
\hline
\end{tabular}

\section{Appendix B. Supplementary material}

Supplementary data to this article can be found online at https://doi.org/10.1016/j.jbusres.2020.04.006.

\section{References}

Antonetti, P., \& Anesa, M. (2017). Consumer reactions to corporate tax strategies: The role of political ideology. Journal of Business Research, 74, 1-10. https://linkinghub. elsevier.com/retrieve/pii/S0148296316306877.

Bargh, J. A., \& Gollwitzer, P. M. (1994). Environmental control of goal-directed action: Automatic and strategic contingencies between situations and behavior. In W. D. Spaulding (Vol. Ed.), Nebraska symposium on motivation. Integrative views of motivation, cognition, and emotion: Vol. 41, (pp. 71-124). University of Nebraska Press.

Bärnighausen, T., \& Sauerborn, R. (2002). One hundred and eighteen years of the German health insurance system: Are there any lessons for middle- and low-income countries? Social Science \& Medicine, 54(10), 1559-1587. https://linkinghub.elsevier.com/ retrieve/pii/S027795360100137X.

Bhattacharjee, A., Berman, J., \& Reed, I. I. (2015). Global character and motivated moral decoupling among liberals and conservatives. ACR North American Advances in Consumer Research, 43, 23-27.

Caruso, E. M., Vohs, K. D., Baxter, B., \& Waytz, A. (2013). Mere exposure to money increases endorsement of free-market systems and social inequality. Journal of Experimental Psychology: General, 142(2), 301-306.

Chin, M. K., Hambrick, D. C., \& Treviño, L. K. (2013). Political ideologies of CEOs: The influence of executives' values on corporate social responsibility. Administrative Science Quarterly, 58(2), 197-232.

Crockett, D., \& Pendarvis, N. (2017). A Research Agenda on Political Ideology in Consumer Research: A Commentary on Jung et al'.s "Blue and Red Voices". Journal of Consumer Research, 44(3), 500-502.

Cumming, G. (2012). Understanding the New Statistics: Effect Sizes, Confidence Intervals, and Meta-Analysis. New York, NY: Routledge.

Currás-Pérez, R., Bigné-Alcañiz, E., \& Alvarado-Herrera, A. (2009). The Role of Self-
Definitional Principles in Consumer Identification with a Socially Responsible Company. J Bus Ethics, 89(4), 547-564. http://link.springer.com/10.1007/s10551008-0016-6.

Dalbert, C., Montada, L., \& Schmitt, M. (1987). Glaube an eine gerechte Welt als Motiv: Validierungskorrelate zweier Skalen [The belief in a just world and validity correlates of two scales]. Psychologische Beitraege, 29, 596-615.

Decker, F. (2018). Jenseits von links und rechts. Lassen sich Parteien noch klassifizieren? Aus Politik und Zeitgeschichte, 46-47. Retrieved from https://www.bpb.de/apuz/ 279819/lassen-sich-parteien-noch-klassifizieren? $\mathrm{p}=$ all (accessed on 20 June 2019).

De Pelsmacker, P., Driesen, L., \& Rayp, G. (2005). Do consumers care about ethics? Willingness to pay for fair-trade coffee. Journal of Consumer Affairs, 39(2), 363-385.

Farah, M. F., \& Newman, A. J. (2010). Exploring consumer boycott intelligence using a socio-cognitive approach. Journal of Business Research, 63(4), 347-355. https:// linkinghub.elsevier.com/retrieve/pii/S0148296309001258.

Feygina, I., Jost, J. T., \& Goldsmith, R. E. (2010). System Justification, the Denial of Global Warming, and the Possibility of "System-Sanctioned Change". Personality and Social Psychology Bulletin, 36(3), 326-338. http://journals.sagepub.com/doi/10. $1177 / 0146167209351435$.

Forsa (2019). Forsa Methods: Forsa.omninet. Retrieved from: https://www.forsa.de/1/ methods/ (accessed on 24 July 2019).

Gromet, D. M., Kunreuther, H., \& Larrick, R. P. (2013). Political ideology affects energyefficiency attitudes and choices. Proceedings of the National Academy of Sciences, 110(23), 9314-9319. http://www.pnas.org/lookup/doi/10.1073/pnas.1218453110.

Gupta, A., Briscoe, F., \& Hambrick, D. C. (2017). Red, blue, and purple firms: Organizational political ideology and corporate social responsibility: Organizational Political Ideology and Corporate Social Responsibility. Strategic Management Journal, 38(5), 1018-1040. http://doi.wiley.com/10.1002/smj.2017.38.issue-5. http://doi. wiley.com/10.1002/smj.2550.

Haack, P., \& Sieweke, J. (2018). The Legitimacy of Inequality: Integrating the 
Perspectives of System Justification and Social Judgment: The Legitimacy of Inequality. Journal of Management Studies, 55(3), 486-516. http://doi.wiley.com/10. 1111/joms.2018.55.issue-3. http://doi.wiley.com/10.1111/joms.12323.

Hafenbrädl, S., \& Waeger, D. (2017). Ideology and the Micro-foundations of CSR: Why Executives Believe in the Business Case for CSR and how this Affects their CSR Engagements. Academy of Management Journal, 60(4), 1582-1606. http://journals. aom.org/doi/10.5465/amj.2014.0691.

Haken, H. (1984). Can synergetics be of use to management theory? Self-organization and management of social systems (pp. 33-41). Berlin, Heidelberg: Springer.

Han, K., Jung, J., Mittal, V., Zyung, J. D., \& Adam, H. (2019). Political Identity and Financial Risk Taking: Insights from Social Dominance Orientation. Journal of Marketing Research, 56(4), 581-601. http://journals.sagepub.com/doi/10.1177/ 0022243718813331.

Hayes, A. F. (2009). Beyond Baron and Kenny: Statistical Mediation Analysis in the New Millennium. Communication Monographs, 76(4), 408-420. http://www.tandfonline. com/doi/abs/10.1080/03637750903310360.

Hayes, A. F. (2018). Introduction to Mediation, Moderation, and Conditional Process Analysis: A Regression-Based Approach (2nd ed.). New York, NY: The Guilford Press.

Hoffmann, S., Balderjahn, I., Seegebarth, B., Mai, R., \& Peyer, M. (2018). Under Which Conditions Are Consumers Ready to Boycott or Buycott? The Roles of Hedonism and Simplicity. Ecological Economics, 147, 167-178. https://linkinghub.elsevier.com/ retrieve/pii/S0921800917310546.

Johnson, P. O., \& Neyman, J. (1936). Tests of certain linear hypotheses and their application to some educational problems. Statistical research memoirs.

Jost, J. T. (2006). The end of the end of ideology. American Psychologist, 61(7), 651-670.

Jost, J. T. (2017). The marketplace of ideology: "Elective affinities" in political psychology and their implications for consumer behavior. Journal of Consumer Psychology, 27(4), 502-520. http://doi.wiley.com/10.1016/j.jcps.2017.07.003.

Jost, J. T., \& Banaji, M. R. (1994). The role of stereotyping in system-justification and the production of false consciousness. British Journal of Social Psychology, 33(1), 1-27.

Jost, J. T., Banaji, M. R., \& Nosek, B. A. (2004). A decade of system justification theory: Accumulated evidence of conscious and unconscious bolstering of the status quo. Political Psychology, 25(6), 881-919. http://www.blackwell-synergy.com/toc/pops/ 25/6. http://doi.wiley.com/10.1111/j.1467-9221.2004.00402.x.

Jost, J. T., Blount, S., Pfeffer, J., \& Hunyady, G. (2003). Fair market ideology: Its cognitive-motivational underpinnings. Research in Organizational Behavior, 25, 53-91. https://linkinghub.elsevier.com/retrieve/pii/S0191308503250024.

Jost, J. T., \& Burgess, D. (2000). Attitudinal ambivalence and the conflict between group and system justification motives in low status groups. Personality and Social Psychology Bulletin, 26(3), 293-305. http://journals.sagepub.com/doi/10.1177/ 0146167200265003.

Jost, J. T., Glaser, J., Kruglanski, A. W., \& Sulloway, F. J. (2003). Political conservatism as motivated social cognition. Psychological Bulletin, 129(3), 339-375.

Jost, J. T., \& Hunyady, O. (2005). Antecedents and Consequences of System-Justifying Ideologies. Current Directions in Psychological Science, 14(5), 260-265. http://journals. sagepub.com/doi/10.1111/j.0963-7214.2005.00377.x.

Jost, J. T., Langer, M., \& Singh, V. (2017). The Politics of Buying, Boycotting, Complaining, and Disputing: An Extension of the Research Program by Jung, Garbarino, Briley, and Wynhausen. Journal of Consumer Research, 44(3), 503-510.

Jost, J. T., \& Thompson, E. P. (2000). Group-Based Dominance and Opposition to Equality as Independent Predictors of Self-Esteem, Ethnocentrism, and Social Policy Attitudes among African Americans and European Americans. Journal of Experimental Social Psychology, 36(3), 209-232. https://linkinghub.elsevier.com/retrieve/pii/ S0022103199914038.

Jung, K., Garbarino, E., Briley, D. A., \& Wynhausen, J. (2017). Blue and red voices: effects of political ideology on consumers' complaining and disputing behavior. Journal of Consumer Research, 44(3), 477-499.

Kay, A. C., \& Jost, J. T. (2003). Complementary justice: effects of" poor but happy” and“ poor but honest" stereotype exemplars on system justification and implicit activation of the justice motive. Journal of personality and social psychology, 85(5), 823-837.

Khan, R., Misra, K., \& Singh, V. (2013). Ideology and Brand Consumption. Psychological Science, 24(3), 326-333. http://journals.sagepub.com/doi/10.1177/ 0956797612457379.

Kim, J. C., Park, B., \& Dubois, D. (2018). How Consumers' Political Ideology and StatusMaintenance Goals Interact to Shape Their Desire for Luxury Goods. Journal of Marketing, 82(6), 132-149. http://journals.sagepub.com/doi/10.1177/ 0022242918799699.

Klein, J. G., Smith, N. C., \& John, A. (2004). Why We Boycott: Consumer Motivations for Boycott Participation. Journal of Marketing, 68(3), 92-109. http://journals.sagepub. com/doi/10.1509/jmkg.68.3.92.34770.

Lange, D., \& Washburn, N. T. (2012). Understanding Attributions of Corporate Social Irresponsibility. AMR, 37(2), 300-326. http://journals.aom.org/doi/10.5465/amr. 2010.0522.

Longchamp, C. (2018). Die Schweizer Politik im Parteientumbler. Republik. Retrieved from: https://www.republik.ch/2018/11/05/die-schweizer-politik-imparteientumbler (accessed on 23 June 2019).

Matten, D., \& Moon, J. (2008). "Implicit" and "Explicit" CSR: A Conceptual Framework for a Comparative Understanding of Corporate Social Responsibility. Academy of Management Review, 33(2), 404-424. http://journals.aom.org/doi/10.5465/amr. 2008.31193458.

McWilliams, A., Siegel, D. S., \& Wright, P. M. (2006). Corporate Social Responsibility: Strategic Implications*. J Management Studies, 43(1), 1-18. http://www.blackwellsynergy.com/toc/joms/43/1. http://doi.wiley.com/10.1111/j.1467-6486.2006. 00580.x.

Mehrabian, A. (1996). Relations among Political Attitudes, Personality, and Psychopathology Assessed With New Measures of Libertarianism and Conservatism.
Basic and Applied Social Psychology, 18(4), 469-491. https://www.tandfonline.com/ doi/full/10.1207/s15324834basp1804 7.

Merrill, J. B. (2016). Liberal, Moderate or Conservative? See How Facebook Labels You. The New York Times. Retrieved online from https://www.nytimes.com/2016/08/ 24/us/politics/facebook-ads-politics.html (accessed on 25. December 2019).

Meynhardt, T. (2009). Public Value Inside: What is Public Value Creation? International Journal of Public Administration, 32(3-4), 192-219. http://www.tandfonline.com/ doi/abs/10.1080/01900690902732632.

Meynhardt, T., Chandler, J. D., \& Strathoff, P. (2016). Systemic principles of value cocreation: Synergetics of value and service ecosystems. Journal of Business Research 69(8), 2981-2989. https://linkinghub.elsevier.com/retrieve/pii/ S0148296316001028.

Meynhardt, T., \& Gomez, P. (2019). Building Blocks for Alternative Four-Dimensional Pyramids of Corporate Social Responsibilities. Business \& Society, 58(2), 404-438. http://journals.sagepub.com/doi/10.1177/0007650316650444.

Mohr, L. A., Webb, D. J., \& Harris, K. E. (2001). Do consumers expect companies to be socially responsible? The impact of corporate social responsibility on buying behavior. Journal of Consumer affairs, 35(1), 45-72.

Morales, A. C., Amir, O., \& Lee, L. (2017). Keeping it real in experimental research-Understanding when, where, and how to enhance realism and measure consumer behavior. Journal of Consumer Research, 44(2), 465-476.

Murphy, P. E., \& Schlegelmilch, B. B. (2013). Corporate social responsibility and corporate social irresponsibility: Introduction to a special topic section. Journal of Business Research, 66(10), 1807-1813. https://linkinghub.elsevier.com/retrieve/pii/ S0148296313000258.

Nuque-Joo, A., Kim, D., \& Choi, S. (2019). Mcdonald's in Germany: Germans, Still Lovin'it? Academy of Strategic Management Journal, 18(2), 1-20.

Ordabayeva, N., \& Fernandes, D. (2018). Better or different? How political ideology shapes preferences for differentiation in the social hierarchy. Journal of Consumer Research, 45(2), 227-250.

Peer, E., Brandimarte, L., Samat, S., \& Acquisti, A. (2017). Beyond the Turk: Alternative platforms for crowdsourcing behavioral research. Journal of Experimental Social Psychology, 70, 153-163. https://linkinghub.elsevier.com/retrieve/pii/ S0022103116303201.

Public Value Atlas (2019a). Public Value Atlas Ranking Overview. Retrieved from: https://www.gemeinwohlatlas.de/en/atlas (accessed on 23 June 2019).

Public Value Atlas (2019b). Methodology. Retrieved online from: https://www. gemeinwohlatlas.de/en/methodik (accessed on 23 June 2019).

Rexer, A. (2013). Wie die Commerzbank in die Krise schlitterte. Süddeutsche Zeitung. Retrieved from: https://www.sueddeutsche.de/wirtschaft/chronik-eines-abstiegswie-die-commerz bank-in-die-krise-schlitterte-1.1701007 (accessed on 23 June 2019).

Roberts, J. A. (1996). Green consumers in the 1990s: Profile and implications for advertising. Journal of Business Research, 36(3), 217-231. https://linkinghub.elsevier. com/retrieve/pii/0148296395001506.

Septianto, F., Northey, G., \& Dolan, R. (2019). The effects of political ideology and message framing on counterfeiting: The mediating role of emotions. Journal of Business Research, 99, 206-214. https://linkinghub.elsevier.com/retrieve/pii/ S014829631930150X.

Shrout, P. E., \& Bolger, N. (2002). Mediation in experimental and nonexperimental studies: New procedures and recommendations. Psychological Methods, 7(4), 422-445.

Spiller, S. A., Fitzsimons, G. J., Lynch, J. G., JR., \& Mcclelland, G. H. (2013). Spotlights, Floodlights, and the Magic Number Zero: Simple Effects Tests in Moderated Regression. Journal of Marketing Research, 50(2), 277-288. http://journals.sagepub. $\mathrm{com} / \mathrm{doi} / 10.1509 / \mathrm{jmr} .12 .0420$.

Vermeir, I., \& Verbeke, W. (2006). Sustainable Food Consumption: Exploring the Consumer "Attitude - Behavioral Intention" Gap. Journal of Agricultural and Environmental ethics, 19(2), 169-194. http://link.springer.com/10.1007/s10806-0055485-3.

Viechtbauer, W. (2010). Conducting meta-analyses in R with the metafor package. Journal of Statistical Software, 36(3), 1-48. http://www.jstatsoft.org/v36/i03/.

Zeit (2019). 420.000 Kunden beteiligen sich an Musterklage. Zeit Online. Retrieved from: https://www.zeit.de/wirtschaft/unternehmen/2019-06/abgasskandal-vw-konzernkunden-musterfeststellungsklage (accessed on 23 June 2019).

Anna Jasinenko is post-doctoral researcher at the University of Lausanne in Switzerland She holds a PhD in management from the HHL Leipzig Graduate School of Management and a master's degree in psychology from the University of Vienna. Anna's major research interest lies in the micro foundations of value perceptions and social evaluations. She is interested how individuals, in their roles as consumers or citizens, perceive and evaluate business behavior and how they incorporate these evaluations in their own behaviors.

Fabian Christandl is professor of economic and social psychology at Hochschule Fresenius - University of Applied Sciences Cologne. He holds a PhD in Management, Economics and Social Sciences and postdoctoral lecture qualification in economic and social psychology from University of Cologne, Faculty of Management, Economics and Social Sciences. His research interests lie in the field of sustainable consumer and working behavior. His research has appeared in several international outlets including the Journal of Experimental Social Psychology, Appetite, Journal of Economic Psychology, Applied Psychology - An International Review, Food Quality and Preference and Computers in Human Behavior.

Timo Meynhardt is Professor and Chair of the Dr. Arend Oetker Chair of Business Psychology and Leadership at HHL Leipzig Graduate School of Management and Managing Director of the Center for Leadership and Values in Society at the University of 
St. Gallen. He studied psychology in Jena, Oxford, and Beijing and obtained his doctorate and habilitation in business administration at the University of St. Gallen. In his research, Timo Meynhardt links psychological and business management topics, especially in the fields of public value management, leadership, and competency diagnostics. His articles have appeared in various journals, such as Business \& Society, International Public Management Journal, Journal of Business Research, International Journal of Public Administration, Journal of Public Administration Research and Theory, and Journal of Management Development. 